\title{
New strategies and developments for peri-implant disease
}

\author{
Arthur Belém NOVAES JUNIOR(a) \\ Umberto Demoner RAMOS(a) \\ Mariana de Sousa RABELO(b) iD \\ Gabriel Bastos FIGUEREDO(c) \\ (a) Universidade de São Paulo - USP, School \\ of Dentistry of Ribeirao Preto, Department \\ of Bucco-Maxillo-Facial Surgery and \\ Traumatology and Periodontology, , \\ Ribeirão Preto, SP, Brazil. \\ (b) Private Practice, São Paulo, SP, Brazil. \\ (c) Universidade de Ribeirão Preto - Unaerp, \\ Ribeirão Preto, SP, Brazil.
}

Declaration of Interests: The authors certify that they have no commercial or associative interest that represents a conflict of interest in connection with the manuscript.

\section{Corresponding Author:}

Arthur Belem Novaes

E-mail:novaesir@forp.usp.br

https://doi.org/10.1590/1807-3107bor-2019.vol33.0071

Submitted: June 11, 2019

Accepted for publication: June 13, 2019

Last revision: June 18, 2019
Abstract: The aim of this illustrated review is to present the new strategies and developments to treatment and diagnosis of periimplant diseases. Periimplant disease is a subject of great concern for modern dentistry. The numbers of implant exhibiting biological complications grows as implant dentistry expands thought-out the world. Diagnosis and treatment of those diseases are still controversial and difficult. We present novel treatment for infection control and biological rationale of additional use of guided bone regeneration, with an illustrative explanation of the treatments presented with two cases.

Keywords: Peri-Iimplantitis; Bone Regeneration; Infection Control.

\section{Introduction}

Periimplantitis is an inflammatory disease that affects the bone and mucosa around osseointegrated implants. It is suggested to be an evolution of a previous periimplant disease, mucositis, and differs from it due to the presence of progressive bone loss. ${ }^{1}$

Mucositis has been shown to be a plaque-induced inflammation of periimplant mucosa. Its reversibility is obtained with proper treatment by means of professional and patient mechanical plaque control. ${ }^{2}$ On the other hand, when having periimplantitis onset, it cannot be reversed with plaque control only and more complex treatment are needed.

Periimplantitis has been an issue of great concern for implant dentistry in the past 20 years. Its prevalence has shown to increase with the number of patients receiving dental implants around the world. It has been difficult to obtain reliable numbers of incidence and prevalence of the disease due to remarked discrepancies on diagnostic criteria. ${ }^{3}$ However, a prevalence of around $20 \%$ in subjects non compliant to a supportive care regime, ${ }^{4}$ and around $14.5 \%$ in compliant patients ${ }^{5}$ is, to date, accepted.

The aetiology appears to be bacterial and its composition has shown to be more complex then in periodontitis. ${ }^{6}$.Most of the proposed treatments rely on strategies of disinfection used on periodontitis such as debridement with curettes and use of local/systemic broad-spectrum antibiotics associated or not with anti-infective solutions, such as used for chemical plaque control. The rationale of using adjunctive broad-spectrum antibiotics to treat a site-specific lesion is questionable due to the risk of development of bacterial resistance and the well known side effects for the rest of the body. 
The primary treatment goal is to disinfect and to reduce the inflammation (bleeding on probing). As a secondary goal, restoration of the periimplant tissue lost due to the disease progression, usually with regenerative approaches using biologics and/ or growth factors.

The aim of this review is to present the developments and new strategies to the treatment and diagnosis of periimplant disease, and help to draw lines for future research.

\section{Diagnosis}

Currently, the tools for diagnosing periimplant conditions are still the periodontal probe and the dental x-ray, ${ }^{1}$ both not accurate as it would be desirable for a diagnostic tool. Bleeding on probing has been a measure of periodontal inflammation for decades ${ }^{7}$ and is still the main diagnostic tool for this condition, despite the possibilities of false negative. To overcome those limitations, recently, authors had proposed a system based on optical spectroscopy for quantification of mucosal inflammation around implants. ${ }^{8}$ This system would be failure proof for inconsistencies found on probing, especially in implants, such as excessive force/pressure on probing, and difficulties in the positioning of the probe due to prosthetic reasons.

The spectroscopy system is composed by a light irradiation emitter surrounded by a fluorescence receptor, the diagnosis is based on an algorithm analysis trough a computer that will measure the amount of oxygenated haemoglobin and concentration of oxygenated/non oxygenated haemoglobin in the tissue. ${ }^{9}$ In the future this method might be a user-friendly, chairside, site-specific, diagnostic and prognostic test for periodontitis and periimplantitis.

Other studies are focusing on analysis of gingival crevicular fluid in order to obtain a non-invasive chairside diagnosis..$^{10}$ To date, it is still an expensive and non user-friendly method. Molecular diagnostic may be valuable in the future, but seems to be far from daily basis clinical application.

\section{Treatment}

\section{Disinfection and antiinfective therapies}

As we stated before, peri-implant diseases have microbial aetiology and the treatment primary goal should be cleansing the implant surface for restoring the bone implant contact. Studies demonstrate that mechanical debriding is not sufficient to provide condition for re-osseointegration ${ }^{11}$ or even to solve inflammation, ${ }^{12}$ this can be easily explained by the complexity of the implant surface and difficulty to access areas of the implant, even with surgical approach. ${ }^{13}$

Some authors had proposed the use of titanium brushes mounted on handpiece with irrigation to mechanically treat the contaminated implant surface $^{14}$. The efficiency of this treatment is still unclear. At the authors experience, those brushes seem to polish the implant surface without reducing it (Figure 1). A more radical treatment of the implant surface includes the total removal of implant threads and outer surface by means of a tungsten bur and metal polishing rubber. ${ }^{15,16}$ Clinical data suggests a good defect resolution in small case series, ${ }^{17}$ but reducing the outer surface of the a narrow implant can cause future biomechanical problems leading to factures, especially on internal connection implants. ${ }^{18}$

As a more conservative approach and in an attempt to preserve the implant surface, adjuvant therapies have been proposed to overcome the the mechanical debridement access difficulty and enhance decontamination. They are usually based on therapeutic strategies for treatment the of periodontitis such as systemic ${ }^{19}$ and local antibiotics and disinfectant solution (i.e., Chlorexidine), ${ }^{20}$ with questionable additional effects.

Last decades, as a consequence of the growing worry with the development of microbial resistance, efforts are being made to find novel antibacterial therapies at all fields of medicine, leading to alternative treatments.

One of the options that have been emerged is the antimicrobial photodynamic therapy ${ }^{21}$ (aPDT) that will be the main focus of this review. aPDT consist on the use of a dye, or 

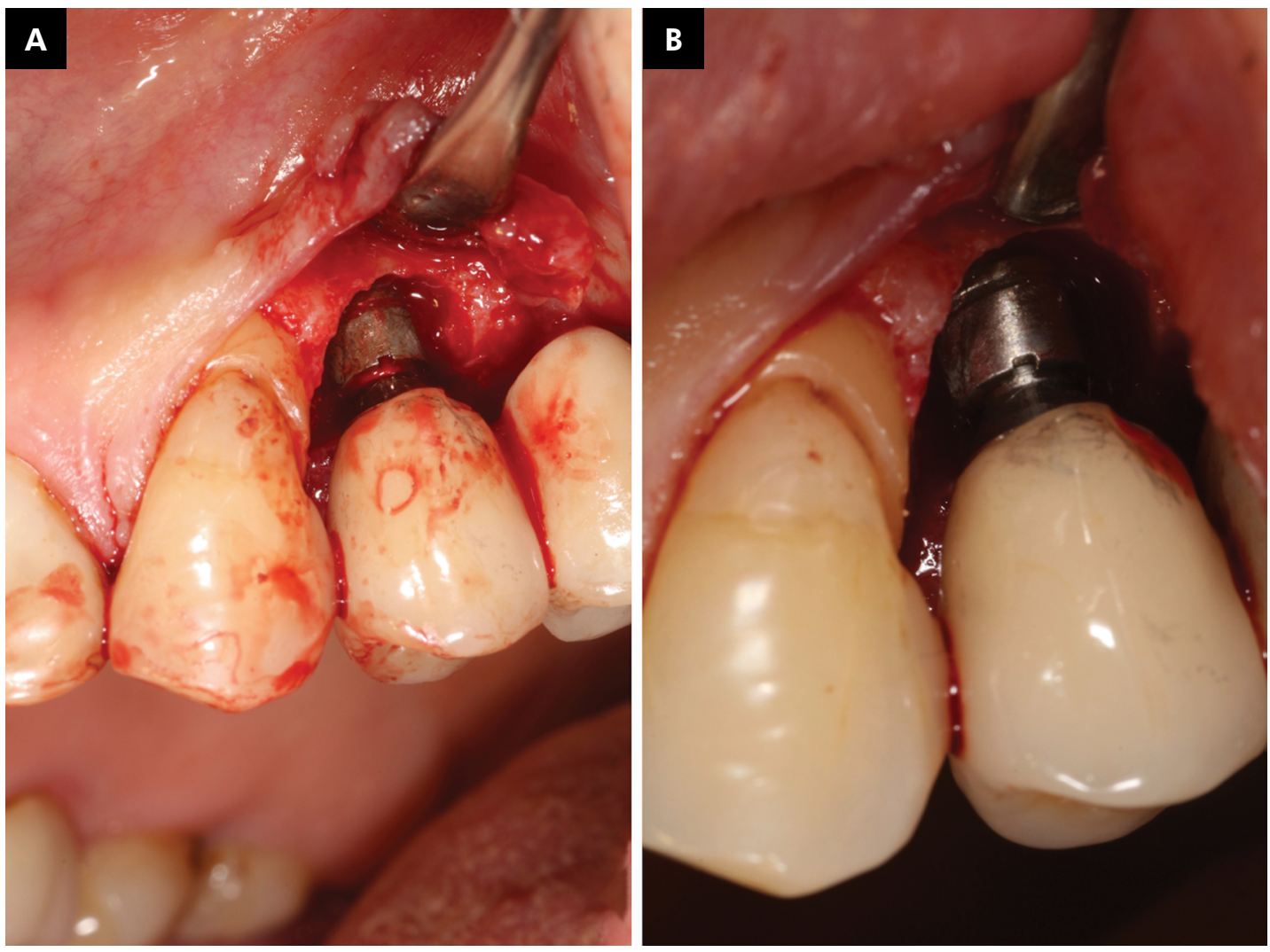

Figure 1. A) implant surface before the use of titanium brush; B) polished surface as result of titanium brush instrumentation.

photosensitizer in association with a light source, usually a laser, to induce photokilling of certain cells, in this case, bacterial pathogens. Despite it involves a series of complex reaction that goes through photophysics and photochemistry, it is important to understand the mechanisms and the factors that may enhance/jeopardize its efficacy and thus, adapt and redesign protocols to maximize efficiency.

There are basically two pathways to photokilling promoted by aPDT, the first one involves reactions with surrounding oxygen molecules, generating superoxide radicals, toxic to bacterial cells. The other pathway involve quenching $\mathrm{H}^{+}$or $\mathrm{OH}^{-}$from aminoacids/proteic molecules, and RNA and DNA, leading to a bacterial death, similar to apoptosis of mammalians cells. ${ }^{21}$ This mechanisms are very different from the ones of common antimicrobials and transform aPDT on an important agent to avoid microbial resistance. ${ }^{22}$
In dentistry, aPDT uses photosensitizers from the family of phenothiazine (ie. Toluidine blue and methylene blue), and the protocols may vary according to the laser device used, power density, and photosensitizer concentration. When dealing with protocols reproducibility, clinicians should lay special attention to the power density used in the studies to obtain similar results.

aPDT has been extensively used on the treatment of infections such as periodontal diseases, with good results, especially when applied in deep pockets. ${ }^{23,24}$ Due to its powerful disinfection potential and ability to target regions not reached by curettes and others mechanical cleansing methods, aPDT has been proposed as an alternative for the treatment of periimplantitis.

As an example of the treatment, this illustrated review will show 2 cases that were treated with an aPDT protocol in order to discuss biological and clinical results obtained. 


\section{Case 1}

A diabetic patient with one internal conical connection implant presented mucosal inflammation with bleeding on probing and great loss of attachment (Figure 2). The first treatment approach was to perform a surgical access in the area without vertical incisions (Figure 3). Then, a mechanical debridement was performed with titanium curettes in order to remove any calculus or visible plaque at the implant surface, followed by the application of a phenothiazine chloride (Figure 4), a preirradiation time of 5 minutes, rinsing with saline and red laser irradiation (Figure 5) in a total power density of $44 \mathrm{~J} / \mathrm{cm}^{2}$ equally distributed on the 6 aspects of the implant (mesial lingual, lingual, disto-lingual, mesial-buccal, buccal, disto-

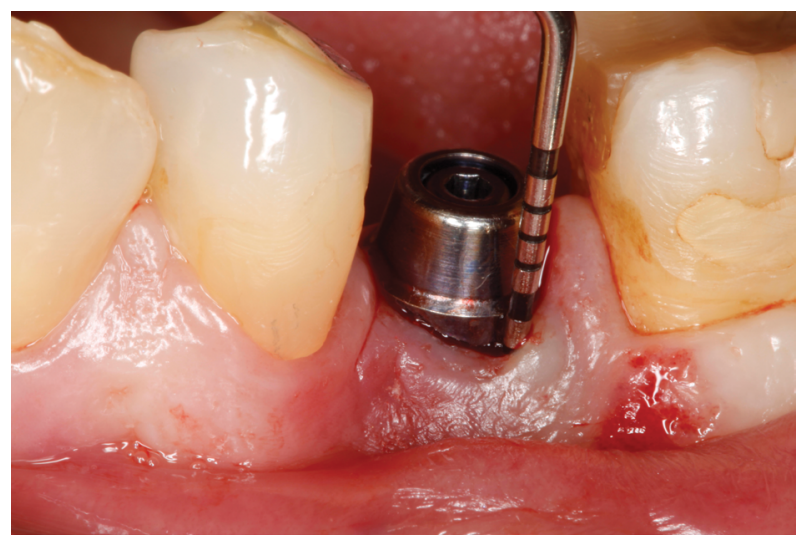

Figure 2. Initial probing depth associated with bleeding.

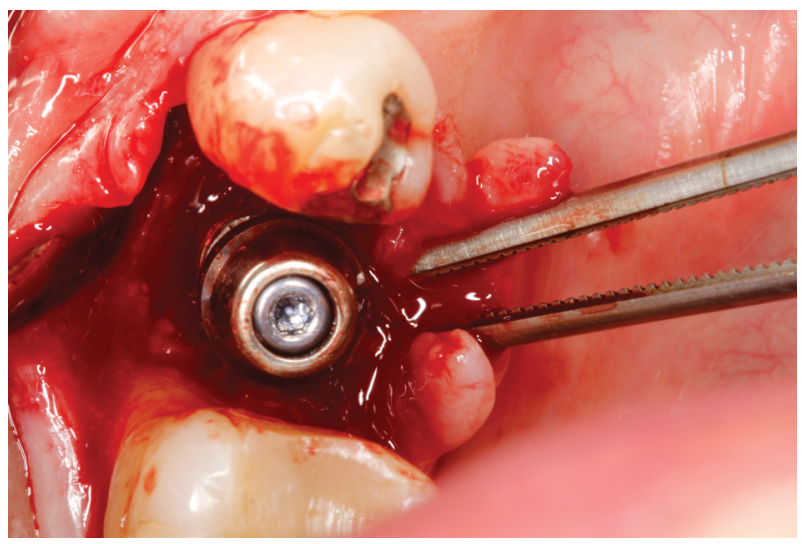

Figure 3. Coronal aspect after opening the flap. buccal). The flap, then was closed with two simple sutures (Figure 6). Six weeks after, the treatment

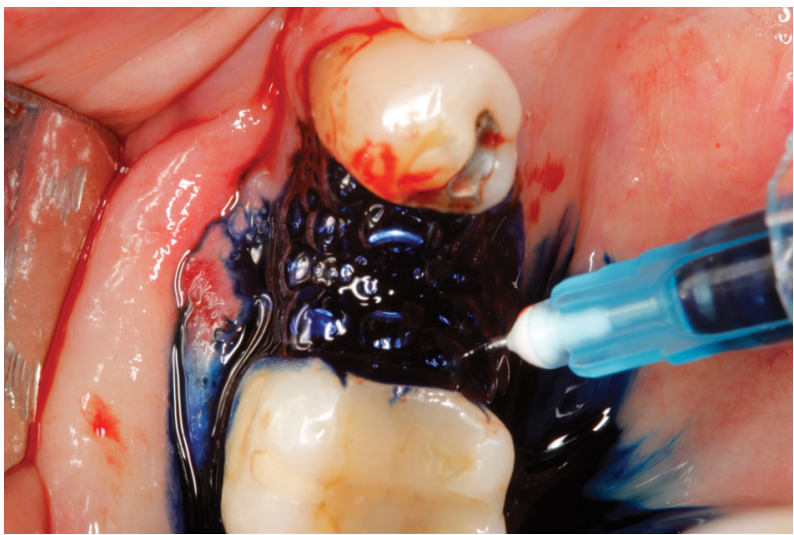

Figure 4. Rinsing with phenotiazinium chloride.

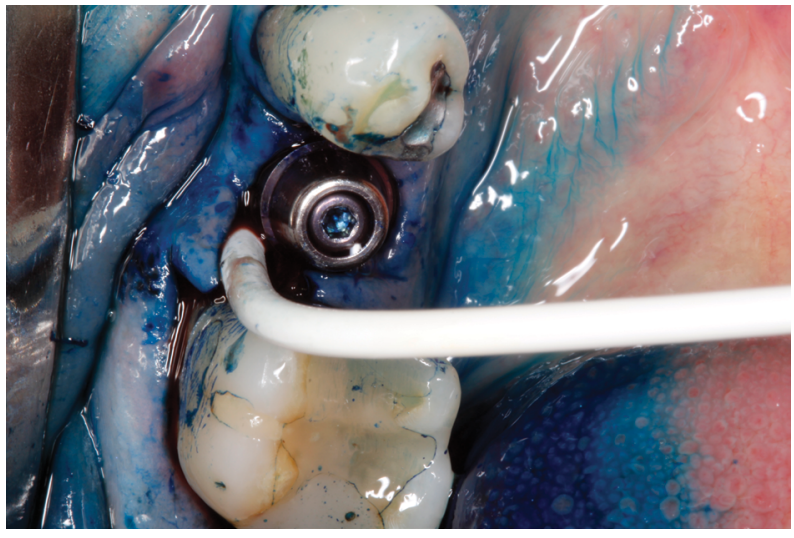

Figure 5. Aspect of the flap after 5 minutes of pre-irradiation time followed by rinsing with saline. The optical fiber in position.

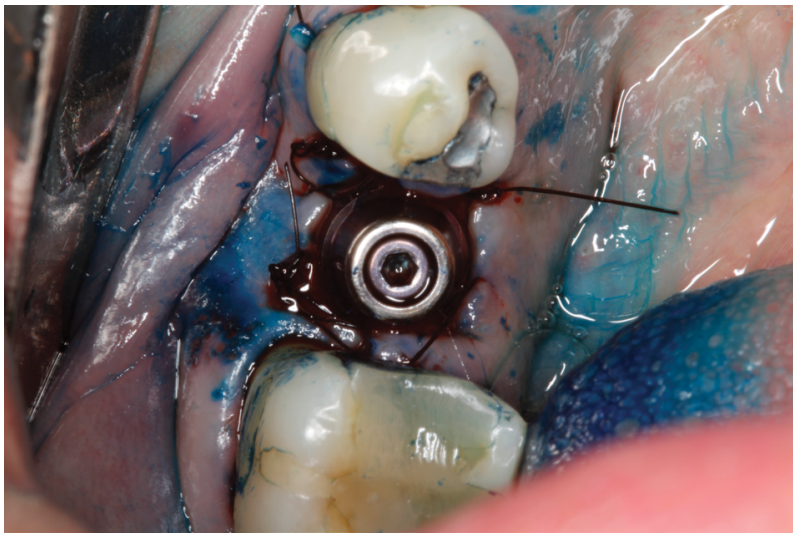

Figure 6. Immediate post-op. 


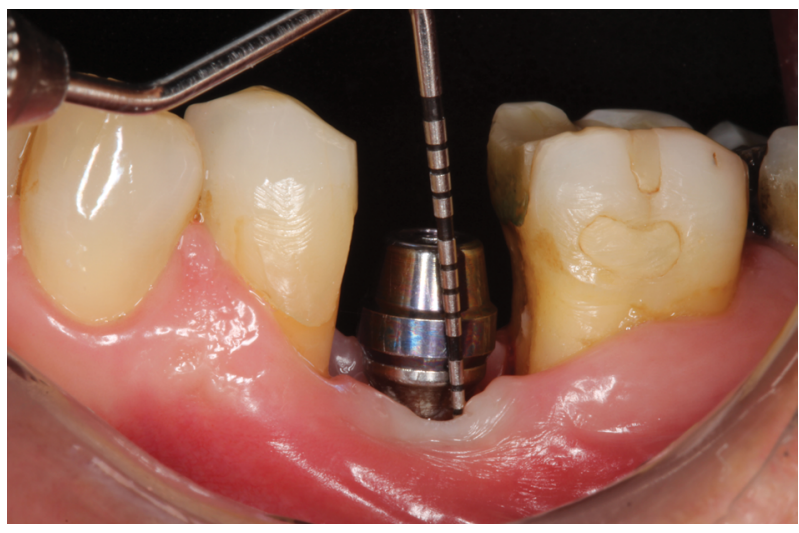

Figure 7. Surgical result of the disinfection showing resolution of inflammation and probing depth, exhibiting mucosal recession.

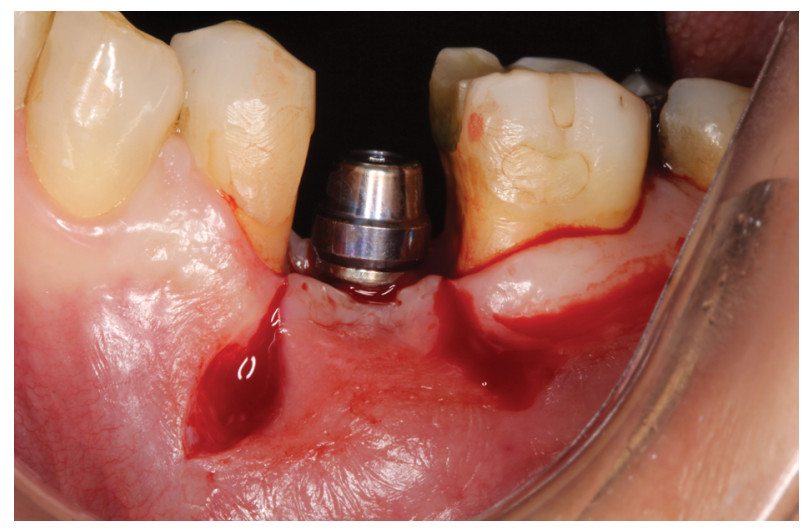

Figure 8. Flap design with two vertical releasing incisions. showed a considerable mucosal recession, but an inflammation resolution (Figure 7). Thus, a new surgical access was performed in an attempt to gain the hard tissue loss due to the disease progression trough guided bone regeneration. Two vertical releasing incisions were made (Figure 8) and a flap was raised to visualize a circumferential defect (Figure 9). The internal connection of the implant was protected and the defect was filled with a bovine bone mineral (Figure 10). A collagen membrane was placed, with a hole in its center to allow the connection of an abutment at the implant (Figure 11). Flap closure was performed with simple sutures (Figure 12) and a new crown was installed. After 6 months, there were no sign of inflammation and the defect was completely filled with biomaterial/ bone (Figure 13).

\section{Case 2}

Patient with a maxillary overdenture installed 2 years before, presented mucosal inflammation and bleeding on probing and bone loss noncompatible with implant connection at the second implant in the right side (Figure 14). Fifteen days before the surgical access, the implant was nonsurgically debrided with plastic curettes to reduce inflammation before surgery. Surgical treatment
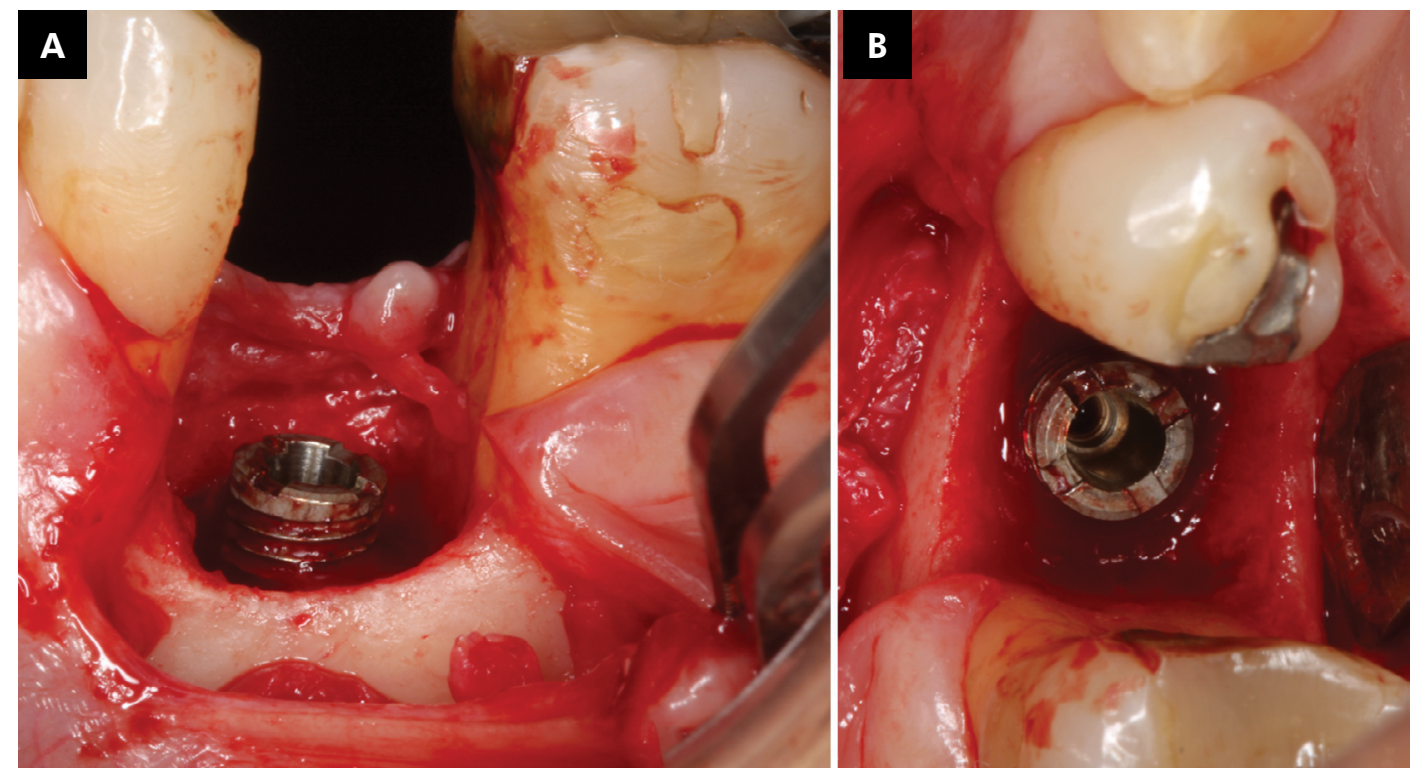

Figure 9. A) coronal aspect of the surgical site; B) Buccal aspect of the surgical site. 

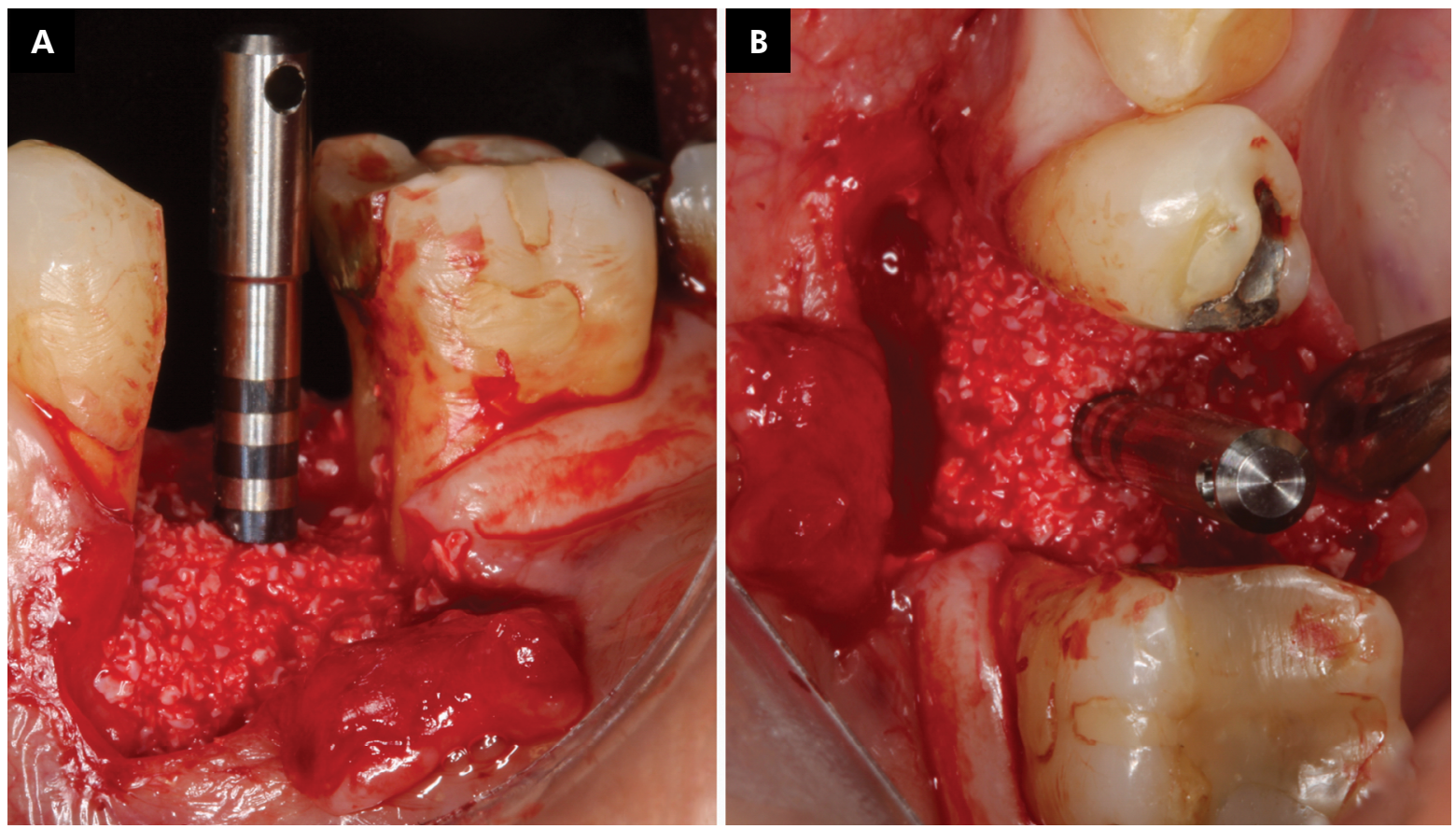

Figure 10. Defect filled with bovine hydroxyapatite, the internal connection was protected with a sulcus measuring pin. A) Coronal Aspect; B) Buccal aspect.

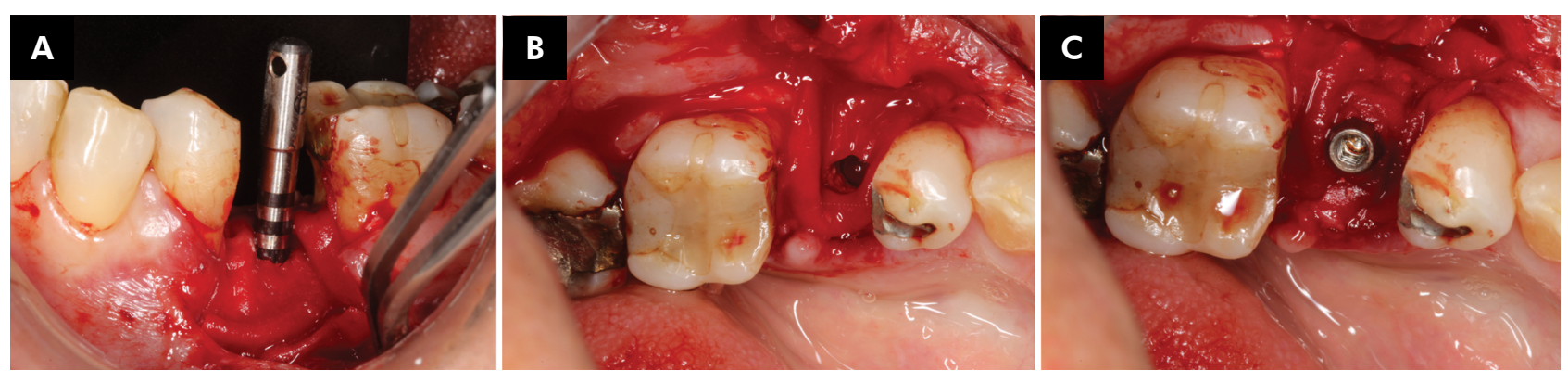

Figure 11. The collagen membrane was positioned with the aid of a sulcus measuring pin (A- buccal aspect; B-coronal aspect) and a hole was made in the center, followed by the connection of the abutment (C).

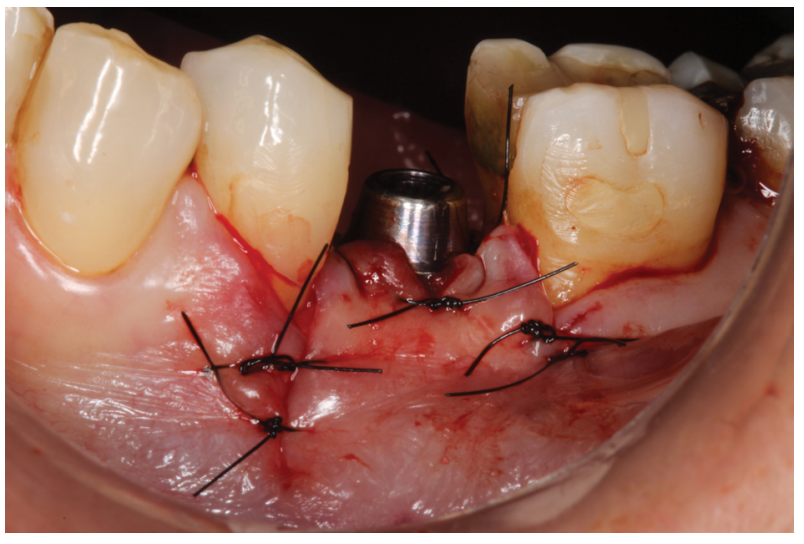

Figure 12. Immediate post-op. was performed two weeks after the non-surgical therapy (Figures 15) with two vertical releasing incisions to access the implant surface (Figure 16), and the same decontamination protocol of case 1 (Figure 17). Guided bone regeneration (GBR) was performed with the aid of a xenograft bone substitute and a collagen membrane (Figure 18) and the flap was closed with simple sutures (Figure 19). 24 months after the surgery the implant presented with no clinical signs of inflammation (Figure 20). 

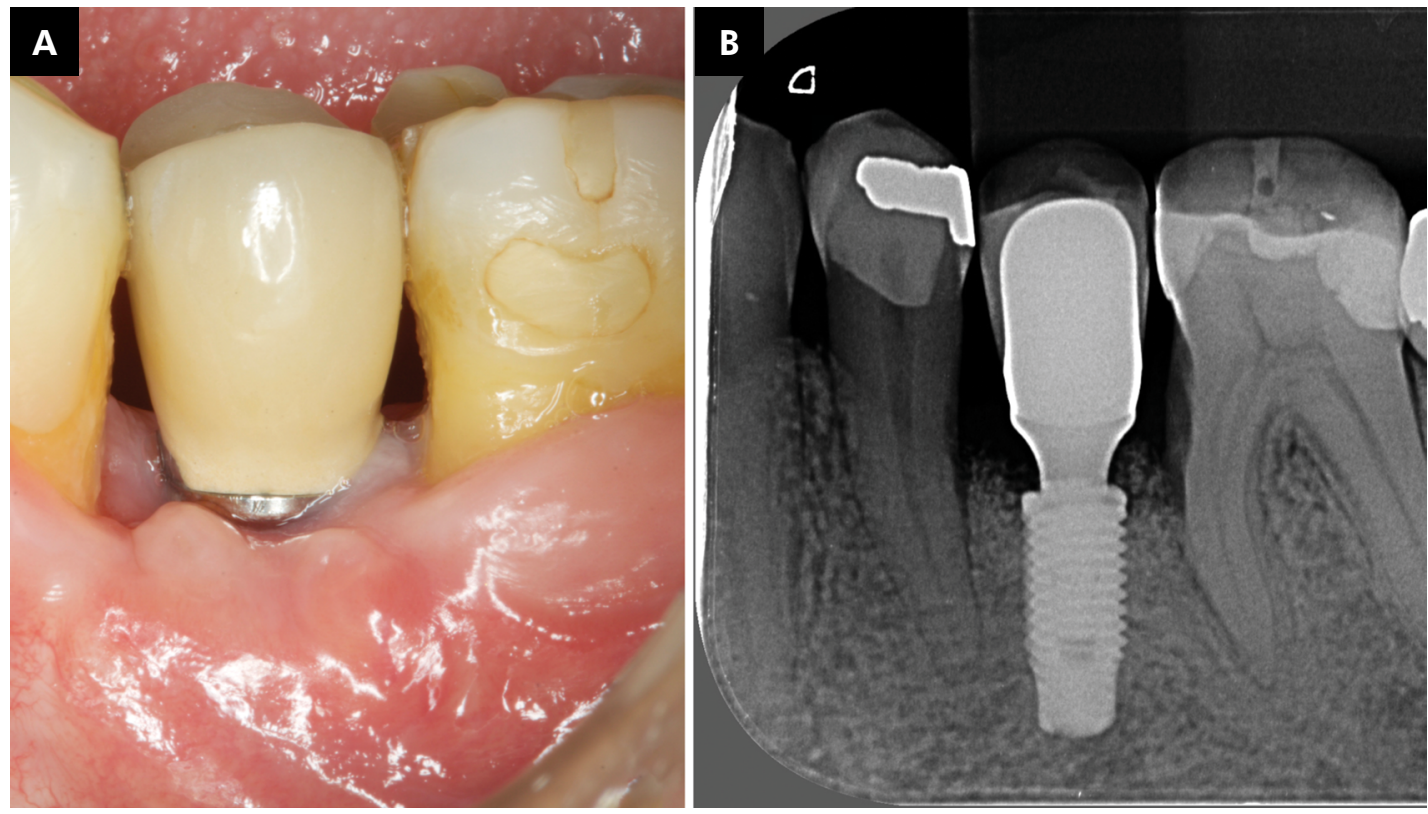

Figure 13. A) Clinical aspect after healing. B)X-ray after healing.

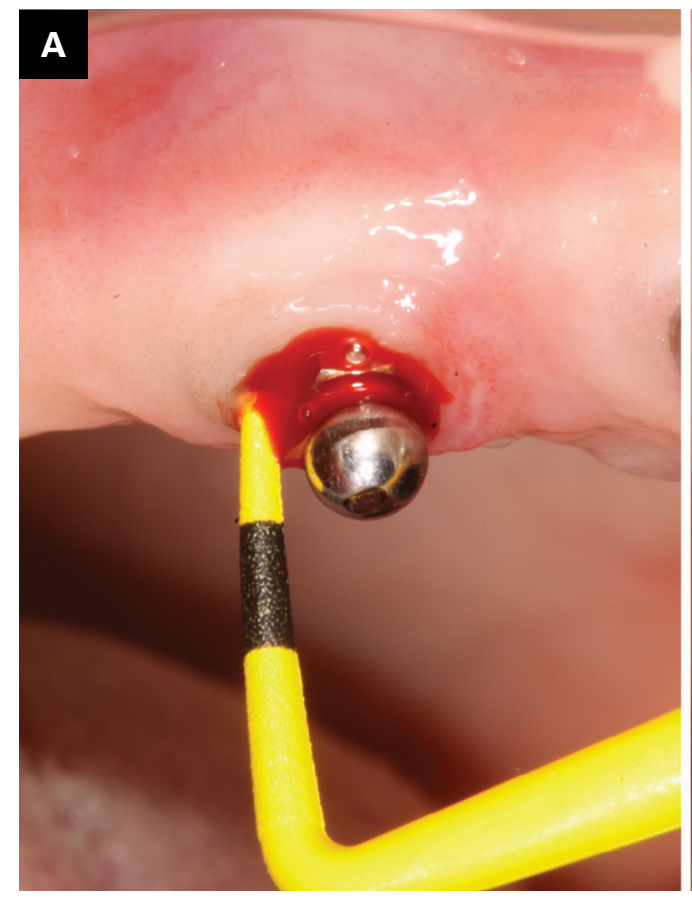

\section{B}

Figure 14. A) clinical aspect showing the difference between healthy and diseased implant; B) Probing depth showing bleeding.

\section{Discussion}

Both cases successfully treated periimplantitis, with radiographical defect filling, and resolution of inflammation. All those features might be considered a successful treatment in its state of art. Thus, we have recently assessed the use of aPDT as an antiinfective treatment, and the effect of the GBRas used on those two cases- on histological and 


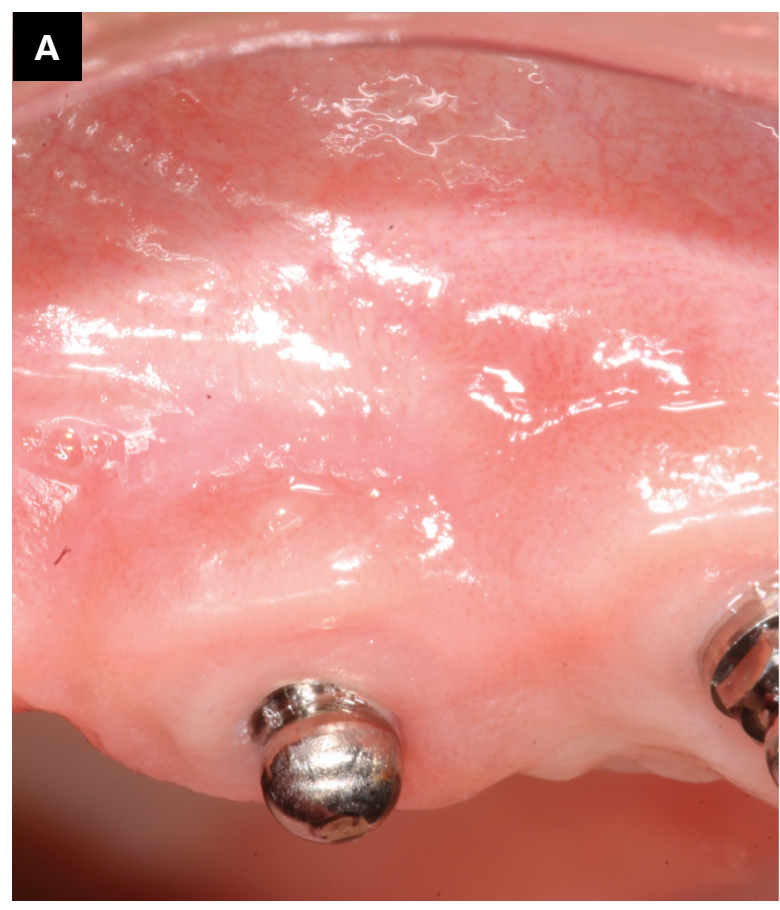

\section{B}

Figure 15. Occlusal (A) and Buccal (B) aspects 1 week after non surgical pre treatment.

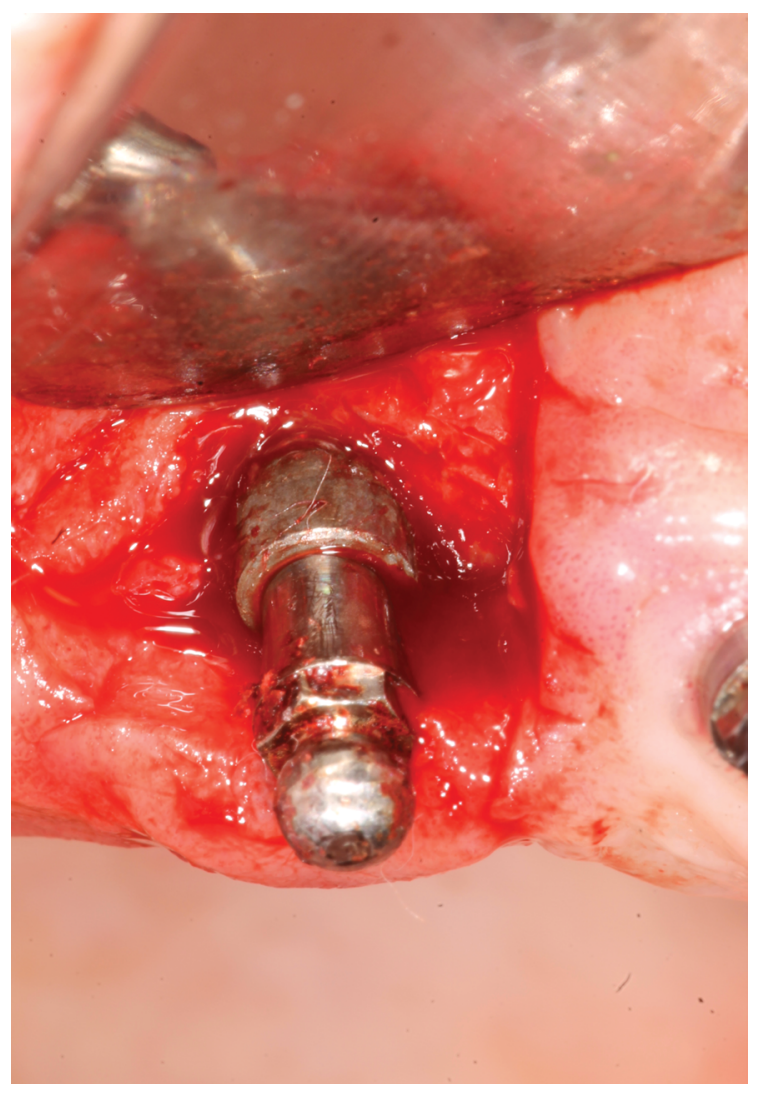

Figure 16. Aspect of the implant with conical connection exhibiting bone loss. clinical outcomes of induced periimplantitis in a dog model. ${ }^{25,26}$ Those studies had shown that the protocol used on those cases was effective on dramatically reducing pathogenic microbiota at periimplantitis lesions ${ }^{25}$ lowering the proportions of bacteria of red and orange complex.

Within the histological data, we could compare the effect of GBR and submerged healing on bone gain and re-osseointegration. Results showed that adding GBR and collagen membrane to the treatment had little or none additional benefits on both outcomes. By means of a statistical analysis with general estimated equation, we could assess the effects of some variables such as early exposure of the implant on the healing period, use of GBR and site of the implant (mesial, distal, lingual and buccal). There was no difference on bone gain and re-osseointegration with or without GBR, buccal sites responded worse independently of the treatment performed and early exposure during healing was the most important factor that modified the treatment outcome. Early exposed implants showed less re-osseointegration, less bone gain and more inflammatory reactions the non-early exposed implant. ${ }^{26}$ Bone quality was similar to in GBR and 

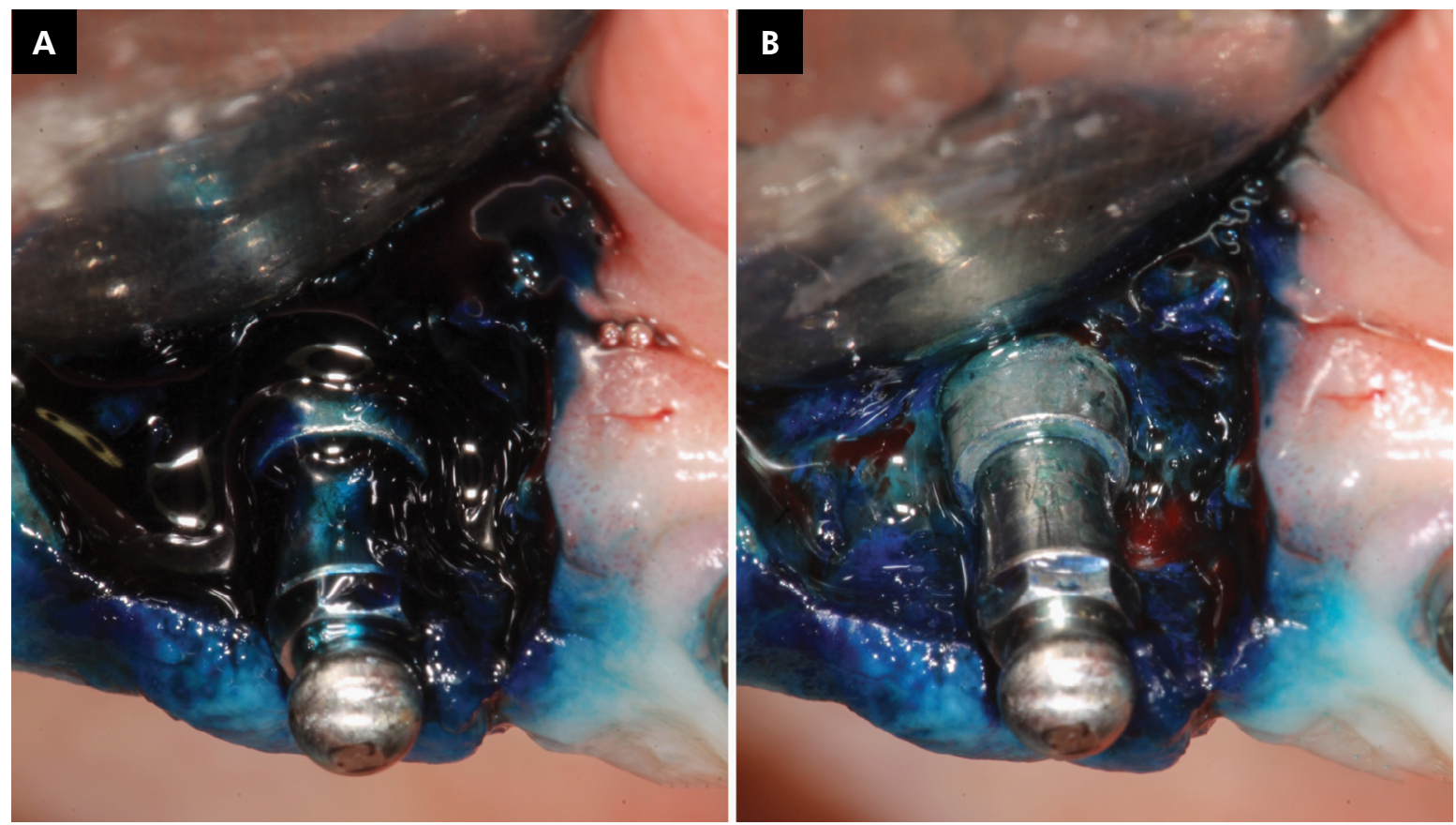

Figure 17. Aspect of the surgical site after rinsing with methylene blue $1 \%$ solution $(A)$ and after a pre irradiation time of 5 minutes and rinsing with saline $(B)$.

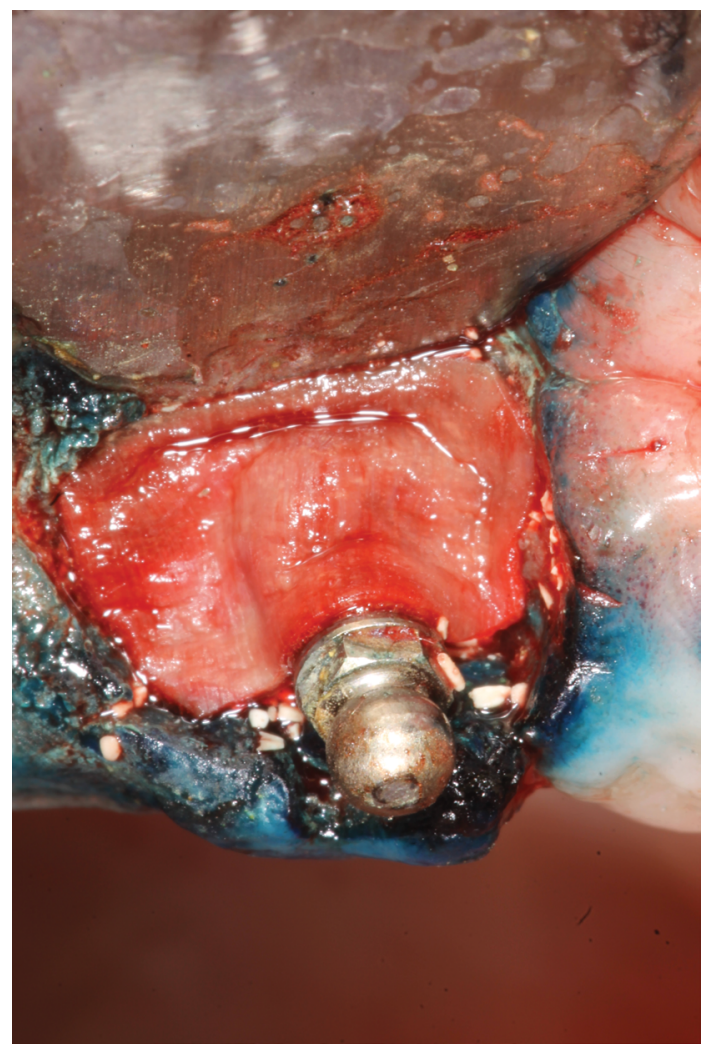

Figure 18. Xenogeneic bone substitute covered by a native collagen membrane.
non-GBR sites, with GBR site exhibiting particles of bovine bone mineral (BBM) embebed in bone/ connective tissue. In this study, no systemic antibiotics were used for the treatment of periimplantitis.

More recently, a randomized clinical trial compared the use and non-use of bone substitute at clinical and radiological parameters after treating periimplantitis. ${ }^{27}$ The results on radiographic bone gain and clinical attachment level gains failed to present differences between treatments, but according to the authors criteria of treatment success (defect fill $\geq 1.0 \mathrm{~mm}$, with PPD values at the implant was $\leq 5 \mathrm{~mm}$, with no BOP - 1 out of 4 sites per implant with BOP grade 1 accepted- and with no suppuration at any of 4 assessed sites per implant ) the use of BBM had significant advantages. ${ }^{27}$ If absence of bleeding on probing (absence of inflammation) was considered as success, no differences could be detected between the groups.

Despite those combined clinical results, the additional benefits of using GBR as adjunctive treatment of periimplantitis lesions is still not a consensus. There is a lack of specific case indications to support predictable results for its use, and the 


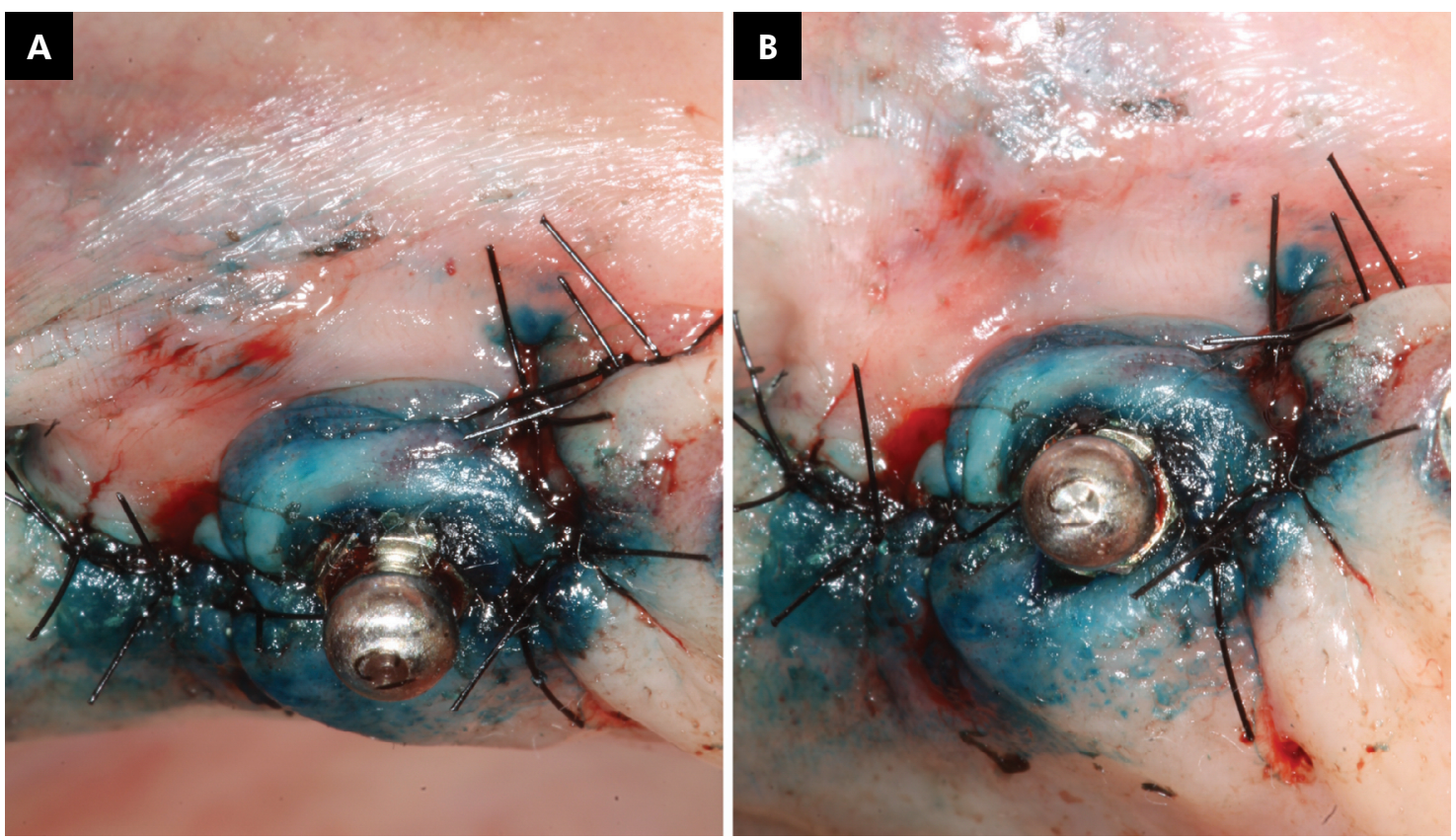

Figure 19. Immediate post op.

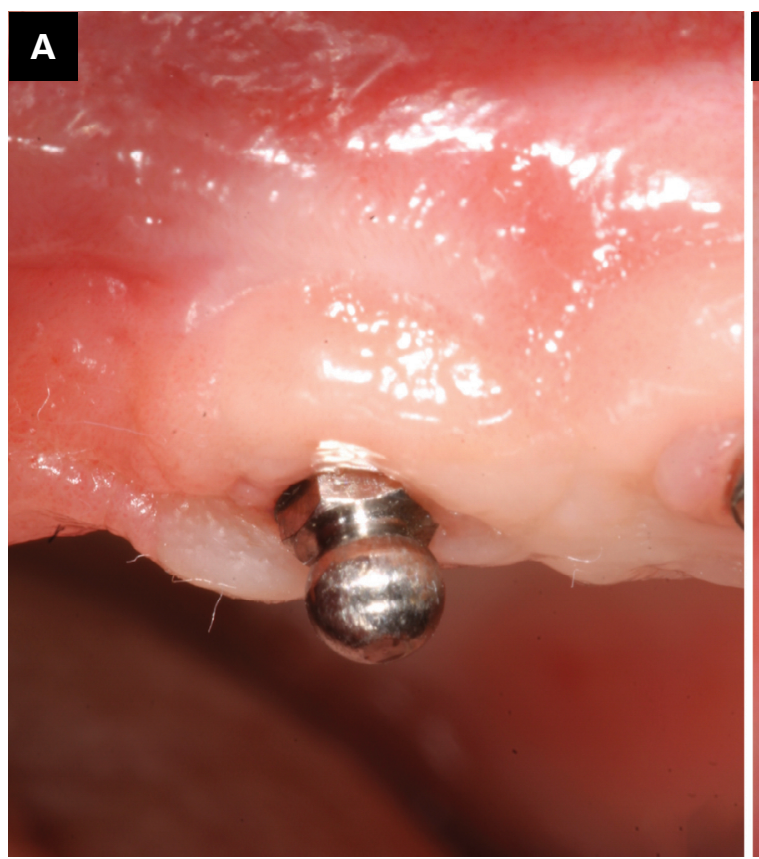

\section{B}

Figure 20. Clinical aspect of health after 2 years.

weight of other factors such as primary closure, flap stability and, as reported in preclinical studies, ${ }^{26}$ flap dehiscence after treatment. It is important to highlight, however, that the GBR is a predictable technique for bone augmentation in a great number of situations, but its additional benefits are questionable when treating periimplantitis considering that the own biological response of the host tissues would be as effective as the aid of a GBR, after proper decontamination. The cost effectiveness of the 
adding a bone substitute and a collagen membrane to obtain limited or no benefits at all on treatment results should be considered.

Future research should aim maneuvers/novel treatments to reduce the incidence of flap dehiscence after surgery in order to maintain stability, especially at the first weeks of healing. The use of growth factors either synthetic (rh-PDGF; amelogenin), or autologous (L-PRF) might be of interest to achieve better and faster healing after decontamination.

\section{References}

1. Berglundh T, Armitage G, Araujo MG, Avila-Ortiz G, Blanco J, Camargo PM, et al. Peri-implant diseases and conditions: Consensus report of workgroup 4 of the 2017 World Workshop on the Classification of Periodontal and Peri-Implant Diseases and Conditions. J Periodontol. 2018 Jun;89 Suppl 1:S313-8. https://doi.org/10.1002/JPER.17-0739

2. Salvi GE, Ramseier CA. Efficacy of patient-administered mechanical and/or chemical plaque control protocols in the management of peri-implant mucositis: a systematic review. J Clin Periodontol. 2015 Apr;42 Suppl 16:S187-201. https://doi.org/10.1111/icpe.12321

3. Derks J, Tomasi C. Peri-implant health and disease: a systematic review of current epidemiology. J Clin Periodontol. 2015 Apr; 42 Suppl 16:S158-71. https://doi.org/10.1111/icpe.12334

4. Rokn A, Aslroosta H, Akbari S, Najafi H, Zayeri F, Hashemi K. Prevalence of peri-implantitis in patients not participating in well-designed supportive periodontal treatments: a cross-sectional study. Clin Oral Implants Res. 2017 Mar;28(3):314-9. https://doi.org/10.1111/clr.12800

5. Derks J, Schaller D, Håkansson J, Wennström JL, Tomasi C, Berglundh T. Effectiveness of Implant Therapy Analyzed in a Swedish Population: prevalence of Peri-implantitis. J Dent Res. 2016 Jan;95(1):43-9. https://doi.org/10.1177/0022034515608832

6. Koyanagi T, Sakamoto M, Takeuchi Y, Ohkuma M, Izumi Y. Analysis of microbiota associated with peri-implantitis using $16 \mathrm{~S} r R N A$ gene clone library. J Oral Microbiol. 2010 May;2(1):2. https://doi.org/10.3402/jom.v2i0.5104

7. Joss A, Adler R, Lang NP. Bleeding on probing. A parameter for monitoring periodontal conditions in clinical practice. J Clin Periodontol. 1994 Jul;21(6):402-8. https://doi.org/10.1111/j.1600-051X.1994.tb00737.x

8. Nogueira-Filho G, Xiang XM, Shibli JA, Duarte PM, Sowa MG, Ferrari DS, et al. On site noninvasive assessment of peri-implant inflammation by optical spectroscopy. J Periodontal Res. 2011 Jun;46(3):382-8. https://doi.org/10.1111/j.1600-0765.2011.01361.x

9. Liu KZ, Xiang XM, Man A, Sowa MG, Cholakis A, Ghiabi E, et al. In vivo determination of multiple indices of periodontal inflammation by optical spectroscopy. J Periodontal Res. 2009 Feb;44(1):117-24. https://doi.org/10.1111/j.1600-0765.2008.01112.x

10. Zani SR, Moss K, Shibli JA, Teixeira ER, de Oliveira Mairink R, Onuma T, et al. Peri-implant crevicular fluid biomarkers as discriminants of peri-implant health and disease. J Clin Periodontol. 2016 Oct;43(10):825-32. https://doi.org/10.1111/icpe.12586

11. Persson LG, Berglundh T, Lindhe J, Sennerby L. Re-osseointegration after treatment of peri-implantitis at different implant surfaces. An experimental study in the dog. Clin Oral Implants Res. 2001 Dec;12(6):595-603. https://doi.org/10.1034/j.1600-0501.2001.120607.x

12. Heitz-Mayfield LJ, Lang NP. Surgical and nonsurgical periodontal therapy. Learned and unlearned concepts. Periodontol 2000.2013 Jun;62(1):218-31. https://doi.org/10.1111/prd.12008

13. Steiger-Ronay V, Merlini A, Wiedemeier DB, Schmidlin PR, Attin T, Sahrmann P. Location of unaccessible implant surface areas during debridement in simulated peri-implantitis therapy. BMC Oral Health. 2017 Nov;17(1):137. https://doi.org/10.1186/s12903-017-0428-8

14. An YZ, Lee JH, Heo YK, Lee JS, Jung UW, Choi SH. Surgical Treatment of Severe Peri-Implantitis Using a Round Titanium Brush for Implant Surface Decontamination: A Case Report With Clinical Reentry. J Oral Implantol. 2017 Jun;43(3):218-25. https://doi.org/10.1563/aaid-joi-D-16-00163

15. Pommer B, Haas R, Mailath-Pokorny G, Fürhauser R, Watzek G, Busenlechner D, et al. Periimplantitis Treatment: LongTerm Comparison of Laser Decontamination and Implantoplasty Surgery. Implant Dent. 2016 Oct;25(5):646-9. https://doi.org/10.1097/ID.0000000000000461

16. Costa-Berenguer X, García-García M, Sánchez-Torres A, Sanz-Alonso M, Figueiredo R, Valmaseda-Castellón E. Effect of implantoplasty on fracture resistance and surface roughness of standard diameter dental implants. Clin Oral Implants Res. 2018 Jan;29(1):46-54. https://doi.org/10.1111/clr.13037

17. Schwarz F, John G, Becker J. Reentry after combined surgical resective and regenerative therapy of advanced peri-implantitis: a retrospective analysis of five cases. Int J Periodontics Restorative Dent. 2015 Sep-Oct;35(5):647-53. https://doi.org/10.11607/prd.2320

18. Chan HL, Oh WS, Ong HS, Fu JH, Steigmann M, Sierraalta M, et al. Impact of implantoplasty on strength of the implant-abutment complex. Int J Oral Maxillofac Implants. 2013 Nov-Dec;28(6):1530-5. https://doi.org/10.11607/jomi.3227 
19. Heitz-Mayfield LJ, Salvi GE, Mombelli A, Faddy M, Lang NP. Anti-infective surgical therapy of peri-implantitis. A 12-month prospective clinical study. Clin Oral Implants Res. 2012 Feb;23(2):205-10. https://doi.org/10.1111/i.1600-0501.2011.02276.x

20. Carcuac O, Abrahamsson I, Charalampakis G, Berglundh T. The effect of the local use of chlorhexidine in surgical treatment of experimental peri-implantitis in dogs. J Clin Periodontol. 2015 Feb;42(2):196-203. https://doi.org/10.1111/icpe.12332

21. Wainwright M. Photodynamic antimicrobial chemotherapy (PACT). J Antimicrob Chemother. 1998 Jul;42(1):13-28. https://doi.org/10.1093/jac/42.1.13

22. Wainwright M, Crossley KB. Photosensitising agents - circumventing resistance and breaking down biofilms: a review. Int Biodeterior Biodegradation. 2004;53(2):53. https://doi.org/10.1016/j.ibiod.2003.11.006

23. Ramos UD, Ayub LG, Reino DM, Grisi MF, Taba Junior M, Souza SL, et al. Antimicrobial photodynamic therapy as an alternative to systemic antibiotics: results from a double-blind, randomized, placebo-controlled, clinical study on type 2 diabetics. J Clin Periodontol. 2016 Feb;43(2):147-55. https://doi.org/10.1111/icpe.12498

24. Moreira AL, Novaes Junior AB, Grisi MF, Taba Junior M, Souza SL, Palioto DB, et al. Antimicrobial photodynamic therapy as an adjunct to non-surgical treatment of aggressive periodontitis: a split-mouth randomized controlled trial. J Periodontol. 2015 Mar;86(3):376-86. https://doi.org/10.1902/jop.2014.140392

25. Ramos UD, Suaid F, Wikesiö UM, Susin C, Vital PC, de Souza SL, et al. Microbiologic effect of two topical anti-infective treatments on ligature-induced peri-implantitis: A pilot study in dogs. J Periodontol. 2018 Aug;89(8):995-1002. https://doi.org/10.1002/JPER.17-0630

26. Ramos UD, Suaid FA, Wikesjö UM, Susin C, Taba M Jr, Novaes AB Jr. Comparison between two antimicrobial protocols with or without guided bone regeneration in the treatment of peri-implantitis: a histomorphometric study in dogs. Clin Oral Implants Res. 2017 Nov;28(11):1388-95. https://doi.org/10.1111/clr.12998

27. Renvert S, Roos-Jansåker AM, Persson GR. Surgical treatment of peri-implantitis lesions with or without the use of a bone substitute-a randomized clinical trial. J Clin Periodontol. 2018 Oct;45(10):1266-74. https://doi.org/10.1111/icpe.12986 